NASA/TM-1999-206581

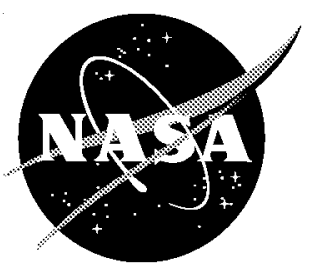

Initial Flight Test of the Production Support Flight Control Computers at NASA Dryden Flight Research Center

John Carter and Mark Stephenson Dryden Flight Research Center

Edwards, California 


\section{The NASA STI Program Office ... in Profile}

Since its founding, NASA has been dedicated to the advancement of aeronautics and space science. The NASA Scientific and Technical Information (STI) Program Office plays a key part in helping NASA maintain this important role.

The NASA STI Program Office is operated by Langley Research Center, the lead center for NASA's scientific and technical information. The NASA STI Program Office provides access to the NASA STI Database, the largest collection of aeronautical and space science STI in the world. The Program Office is also NASA's institutional mechanism for disseminating the results of its research and development activities. These results are published by NASA in the NASA STI Report Series, which includes the following report types:

- TECHNICAL PUBLICATION. Reports of completed research or a major significant phase of research that present the results of NASA programs and include extensive data or theoretical analysis. Includes compilations of significant scientific and technical data and information deemed to be of continuing reference value. NASA's counterpart of peer-reviewed formal professional papers but has less stringent limitations on manuscript length and extent of graphic presentations.

- TECHNICAL MEMORANDUM. Scientific and technical findings that are preliminary or of specialized interest, e.g., quick release reports, working papers, and bibliographies that contain minimal annotation. Does not contain extensive analysis.

- CONTRACTOR REPORT. Scientific and technical findings by NASA-sponsored contractors and grantees.
- CONFERENCE PUBLICATION.

Collected papers from scientific and technical conferences, symposia, seminars, or other meetings sponsored or cosponsored by NASA.

- SPECIAL PUBLICATION. Scientific, technical, or historical information from NASA programs, projects, and mission, often concerned with subjects having substantial public interest.

- TECHNICAL TRANSLATION. Englishlanguage translations of foreign scientific and technical material pertinent to NASA's mission.

Specialized services that complement the STI Program Office's diverse offerings include creating custom thesauri, building customized databases, organizing and publishing research results ... even providing videos.

For more information about the NASA STI Program Office, see the following:

- Access the NASA STI Program Home Page at http://www.sti.nasa.gov

- E-mail your question via the Internet to help@sti.nasa.gov

- Fax your question to the NASA Access Help Desk at (301) 621-0134

- Telephone the NASA Access Help Desk at (301) 621-0390

- Write to:

NASA Access Help Desk

NASA Center for AeroSpace Information 7121 Standard Drive

Hanover, MD 21076-1320 


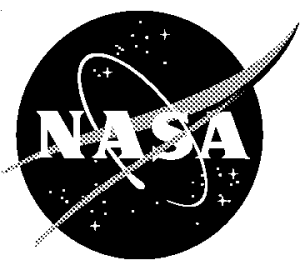

\section{Initial Flight Test of the Production Support Flight Control Computers at NASA Dryden Flight Research Center}

John Carter and Mark Stephenson Dryden Flight Research Center

Edwards, California

National Aeronautics and

Space Administration

Dryden Flight Research Center

Edwards, California 93523-0273 


\section{NOTICE}

Use of trade names or names of manufacturers in this document does not constitute an official endorsement of such products or manufacturers, either expressed or implied, by the National Aeronautics and Space Administration.

Available from the following:

NASA Center for AeroSpace Information (CASI)

7121 Standard Drive

Hanover, MD 21076-1320

(301) 621-0390
National Technical Information Service (NTIS) 5285 Port Royal Road Springfield, VA 22161-2171 (703) $487-4650$ 


\title{
INITIAL FLIGHT TEST OF THE PRODUCTION SUPPORT FLIGHT CONTROL COMPUTERS AT NASA DRYDEN FLIGHT RESEARCH CENTER
}

\author{
John Carter $^{*}$ and Mark Stephenson ${ }^{\dagger}$ \\ NASA Dryden Flight Research Center \\ Edwards, California
}

\begin{abstract}
$\underline{\text { Abstract }}$
The NASA Dryden Flight Research Center has completed the initial flight test of a modified set of F/A-18 flight control computers that gives the aircraft a research control law capability. The production support flight control computers (PSFCC) provide an increased capability for flight research in the control law, handling qualities, and flight systems areas. The PSFCC feature a research flight control processor that is "piggybacked" onto the baseline F/A-18 flight control system. This research processor allows for pilot selection of research control law operation in flight. To validate flight operation, a replication of a standard F/A-18 control law was programmed into the research processor and flighttested over a limited envelope. This paper provides a brief description of the system, summarizes the initial flight test of the PSFCC, and describes future experiments for the PSFCC.
\end{abstract}

\section{$\underline{\text { Nomenclature }}$}

$\begin{array}{ll}\text { A/D } & \text { analog to digital } \\ \text { D/A } & \text { digital to analog } \\ \text { DDI } & \text { digital display indicator } \\ \text { FCF } & \text { functional check flight } \\ g & \begin{array}{l}\text { gravitational acceleration constant, } \\ 32.2 \mathrm{ft} / \mathrm{sec}^{2}\end{array} \\ \text { HARV } & \text { High Alpha Research Vehicle } \\ \text { KCAS } & \text { knots calibrated airspeed } \\ \text { NATOPS } & \begin{array}{c}\text { Naval Air Training and Operating } \\ \end{array} \\ & \text { Procedures Standardization }\end{array}$

\footnotetext{
* Aerospace Engineer. E-mail: john_carter@dfrc.nasa,gov.

†Aerospace Engineer. E-mail: mark_stephenson@ @dfrc. nasa.gov.

Copyright (C) 1999 by the American Institute of Aeronautics and Astronautics, Inc. No copyright is asserted in the United States under Title 17, U.S. Code. The U.S. Government has a royalty-free license to exercise all rights under the copyright claimed herein for Governmental purposes. All other rights are reserved by the copyright owner.
}

PSFCC production support flight control computers

RFCS research flight control system

\section{$\underline{\text { Introduction }}$}

Control law software development on aircraft historically has been extremely expensive and timeconsuming because of the numerous staff hours devoted to design, implementation, and test of flight-critical software. Large amounts of hours are required because of the flight-critical nature of control law function. Extremely thorough testing is required because a control law software malfunction could lead to a loss of aircraft, property, or aircrew. Development of an easily modifiable flight control system capable of reverting to a baseline control system can address these issues.

NASA has developed several aircraft for in-flight control law development. Aircraft such as the NT-33A Variable Stability Aircraft, the F-8 Digital Fly-By-Wire aircraft, and the General Purpose Airborne Simulator have been used for in-flight simulation and dynamics studies. ${ }^{1,2}$ Private organizations that do research have developed aircraft such as the variable stability Learjet and the F-16 Variable Stability In-Flight Simulator Test Aircraft (VISTA) that have research flight control computer systems. These systems are designed to allow relatively fast control law modifications while safety of flight is retained through the primary control system. The systems have also been used to modify dynamic characteristics in flight to simulate other airframes.

Engineers at NASA Dryden Flight Research Center (Edwards, California) have had recent experience with a system designed for rapid control law modification that operates the F/A-18 High Alpha Research Vehicle (HARV) aircraft. ${ }^{3,4}$ The HARV is a modified F/A-18 aircraft with thrust-vectoring paddles that was designed for flight test at high angles of attack. Flight control computers of the HARV were modified to include a pilot-selectable research control law processor. This system allowed the HARV to operate with conventional 
F/A-18 control laws for all phases of flight and have research control laws available at specified parts of the flight envelope. Reversion to the conventional control laws was accomplished either manually or automatically with system failure or envelope violation. The HARV design provided a flexible platform for control law algorithm research. The ability to restore aircraft control to a safe, proven system addressed many of the safety-of-flight issues associated with experimental control law architectures.

Building on the experience gained from the F/A-18 HARV, the United States Navy and NASA Dryden worked in concert with The Boeing Company (St. Louis, Missouri) ${ }^{+}$and Lockheed Martin Control Systems (Binghamton, New York) to develop a system that could operate on any F/A-18 (model A to model D). This system is called the production support flight control computers (PSFCC). ${ }^{5}$ Several sets of F/A-18 computers have been modified into PSFCC. The PSFCC include production F/A-18 control processors, research processors, software that controls the transition between the primary and research systems, and cockpit interface software for research mode selection. For this demonstration, the research processors have been programmed with a replication of the standard F/A-18 control laws.

To demonstrate the viability of the PSFCC concept, an initial flight test phase has been conducted. This phase was performed in March-April 1998. Four flights were accomplished. A standard U. S. Navy functional check flight (FCF) has been conducted to validate that normal F/A-18 operations are not affected, and research flights have demonstrated PSFCC engage/disengage operation in a envelope limited for flight safety considerations. Flights to investigate handling qualities have been conducted in the F/A-18 replication mode to validate the performance of the research processor.

Several new experiments are being prepared for the PSFCC. The first to be flown will be an experiment using an alternate pilot stick to control the F/A-18 aircraft to investigate handling qualities issues associated with different pilot stick configurations. The second experiment will involve using the PSFCC to produce data that will be used to refine the F/A-18 aerodynamics database. This database will be used for an F/A-18 flexible wing program. Other proposed flight experiments include F/A-18 autonomous formation

\footnotetext{
Formerly McDonnell Douglas Aerospace, which merged with The Boeing Company during these tests.
}

flight and controllers designed using modern and robust control theory.

This paper gives a brief description of the function of the system, presents the results of the initial flight test, and describes the future experiments planned for the PSFCC. Anomalies encountered during ground and flight test are discussed.

Use of trade names or names of manufacturers in this document does not constitute an official endorsement of such products or manufacturers, either expressed or implied, by the National Aeronautics and Space Administration.

\section{Production Support Flight Control Computers Functional Description}

The PSFCC design uses a research processor in addition to the baseline F/A-18 flight control computers. A detailed description of the PSFCC implementation has been published. ${ }^{5}$ The research flight control system can be engaged by the pilot to exercise full-authority control of the aircraft with research flight control laws. For the initial flight test, only the F/A-18 replication mode was flight-tested, which duplicated the basic F/A-18 control laws in the research processor.

Figure 1 shows how the PSFCC are integrated into the F/A-18 aircraft flight control system. The F/A-18 aircraft is controlled by a quadruply redundant flight control computer system. Figure 2 shows the PSFCC modification to the basic flight control computer. The research PACE 1750A processor (Performance Semiconductor Corporation, Sunnyvale, California) is embedded in the same avionics box as the basic $701 \mathrm{E}$ flight control processors (Lockheed Martin Control Systems, Binghamton, New York).

The research control laws are programmed in Ada and are completely independent of the basic control laws. This independence allows new research control laws to be added without affecting the basic flight control system. All information to and from the research processor is handled by the basic flight control system through dual-port random access memory to facilitate communication between the research system and the basic system. This separation also provides good fault isolation of the research processor.

Figure 3 shows all the elements the pilot uses to interface with the PSFCC. Figure 3(a) shows the F/A-18 displays, featuring the digital display indicators (DDIs) 


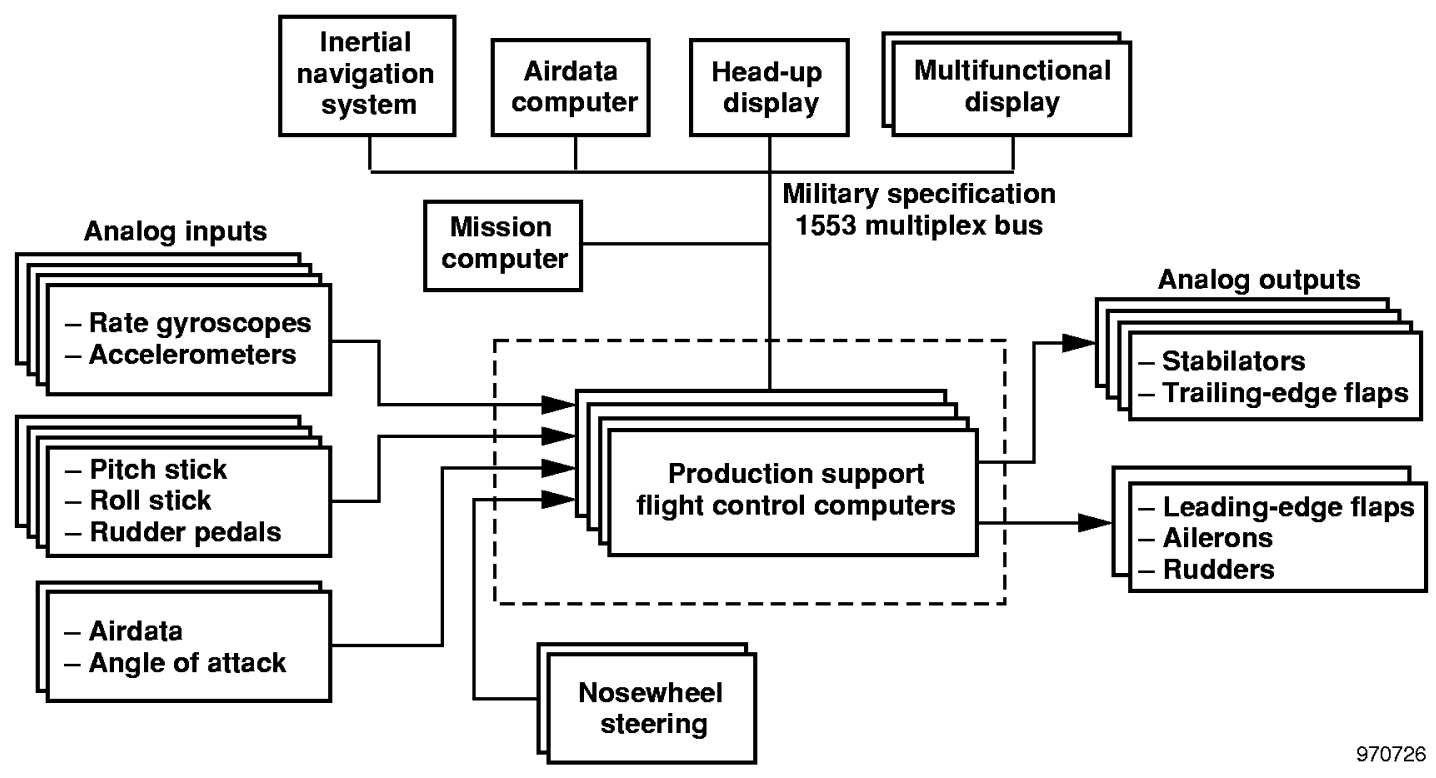

Figure 1. The F/A-18 control system components.

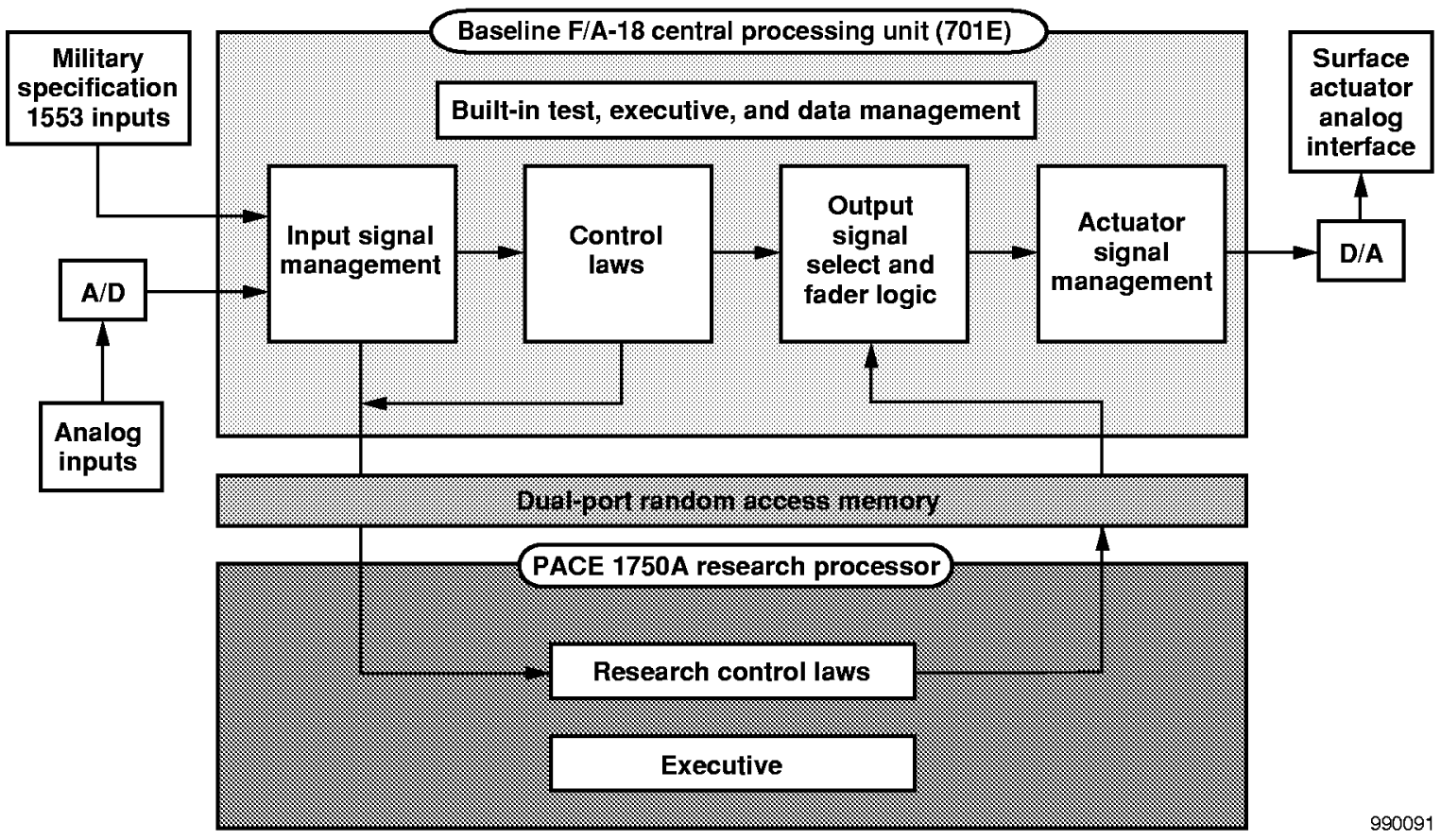

Figure 2. Integration of research processor and baseline F/A-18 systems. ${ }^{3}$ 
and the up-front controller that is used to program buttons for the DDI. Figure 3(b) shows the DDI display with the programmable buttons and "arm" discrete displayed. Figure 3(c) shows the pilot stick with the nosewheel steering button and the paddle switch.

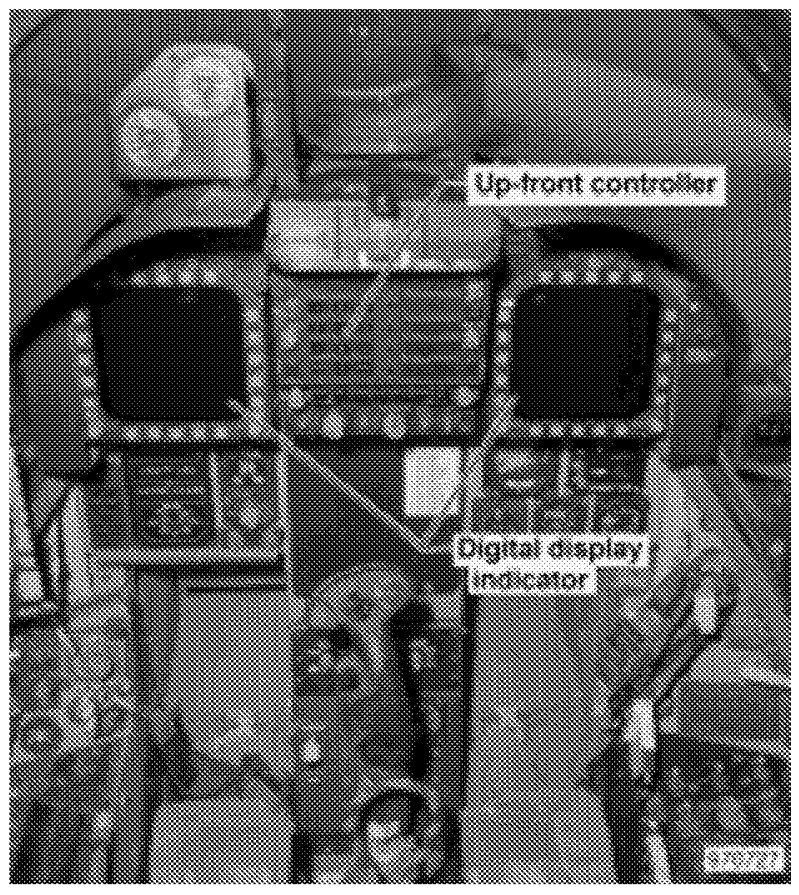

(a) Digital display indicators and up-front controller.

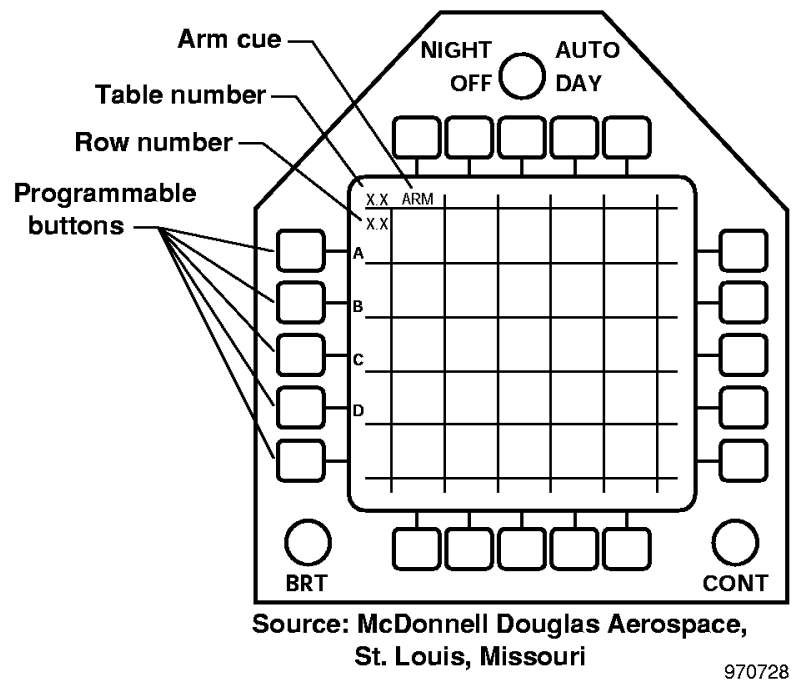

(b) Digital display indicator with program buttons.

Figure 3. The F/A-18 cockpit displays and pilot stick.

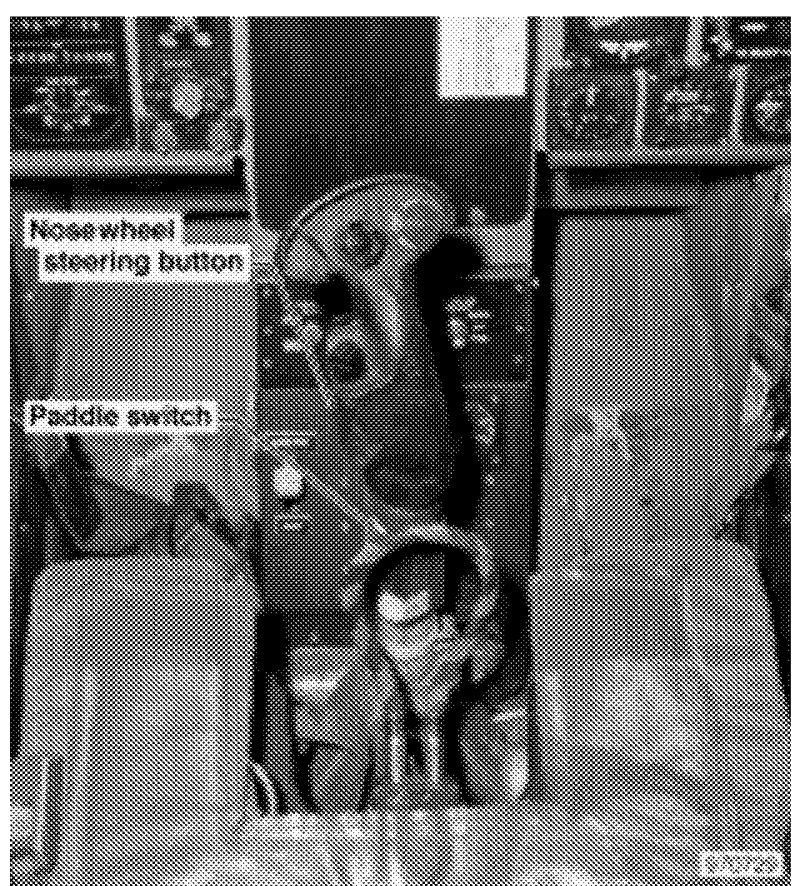

(c) Pilot stick with nosewheel steering button and paddle switch.

Figure 3. Concluded.

The research software has been preprogrammed with two sets of requirements: arm requirements and engage/disengage requirements. When the research mode is requested by selecting a DDI button, all of the arming requirements are checked. The aircraft parameters currently checked for arm/disengage are differential stabilator, normal acceleration, yaw rate, bank angle, altitude, and Mach number. The parameters must meet the requirements to allow the system to be armed (enabled) and then engaged (activated). If the arming requirements are met, the PSFCC will give an "armed" indication on the DDI. The pilot can attempt to engage the mode by pressing the nosewheel steering button at the bottom of the control stick. If all engagement requirements are satisfied, the PSFCC will engage. The pilot may disengage the system by deploying the flaps, activating the spin-recovery mode, or depressing the autopilot disengage switch (paddle switch) at the bottom of the control stick. Automatic disengagements will occur if engage limits are violated or a system failure is detected. Reference 5 provides more detail on PSFCC operation.

\section{"Class B" Envelope}

The baseline processor and all interface software to the research processor had extensive testing to a "class 
A," or flight-critical, level. The initial software version in the research processor did not have the testing necessary to be used for class A aircraft control. Because the research Ada control law software had not been tested to NASA flight-critical standards, the PSFCC could be demonstrated only in a limited, or "class B," envelope. The class B envelope boundary was defined using the assumption that given a software fault during which all surfaces are commanded to worst-case full deflections at their respective rate limits, the aircraft remains within known structural limitations. For the initial PSFCC flight test, body-axis acceleration limits (because of wing modifications) were $\pm 1 \mathrm{~g}$ lateral and $+6 /-3.5 \mathrm{~g}$ normal acceleration.

Figure 4 shows the class $\mathrm{B}$ envelope. The envelope was divided into five regions where handling qualities maneuvers were flown. A 4-g normal disengage acceleration limit was necessary to ensure that the aircraft would stay within the 6- $g$ normal acceleration structural limit in the event of a software fault during high $g$ loading. A procedural limit of 250 knots calibrated airspeed $(K C A S)$ and a maximum altitude limit of 32,500 ft were enforced.

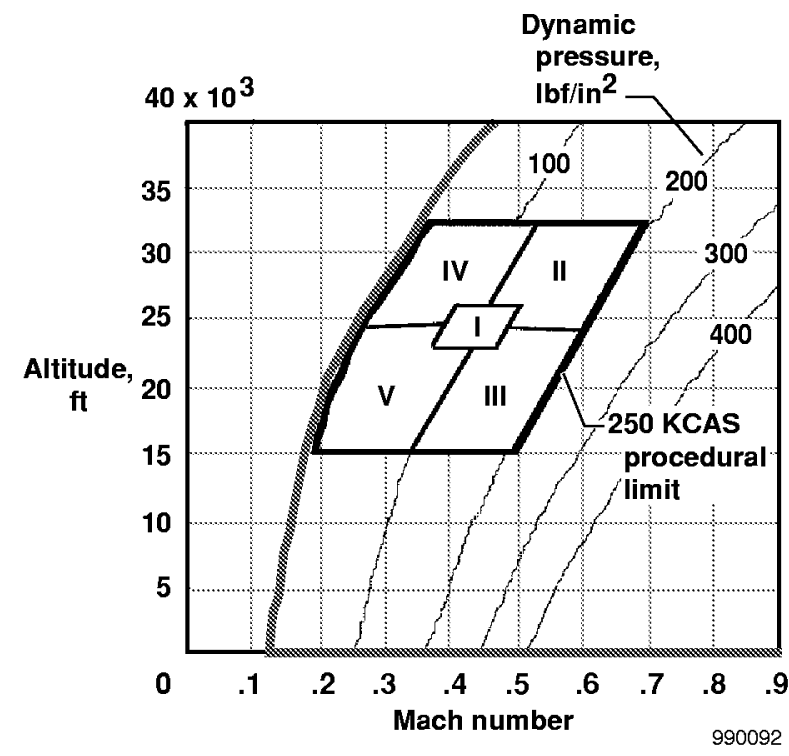

Figure 4. Class B envelope with five handling qualities regions.

\section{Control Room Displays}

Several strip-chart configurations and control room displays that were used to monitor system operation and verify safe flight operations have been designed for use with the PSFCC. Currently, four strip charts show standard parameters for flight control system monitoring. These parameters include aircraft angles, rates, accelerations, airdata, surface deflections, and pilot commands.

In addition, computer monitor displays provide control room personnel with PSFCC status information. The display shown in figure 5 provides current status of the PSFCC hardware. This display shows the 701E and $1750 \mathrm{~A}$ processor fault information such as sensor failures, processor timeouts, and validity bits. The display shown in figure 6 provides $1750 \mathrm{~A}$ processor research software information such as armed/engaged status, operating research mode, and reasons for disengagement. This information is used to augment the displays available to the pilot that give limited insight into system operation and failure messages. In addition to these two displays, other displays can be used that show current actuator commands and research software limits as well as baseline F/A-18 and research software symmetric stabilator commands.

\section{Verification and Validation Testing}

Extensive verification and validation ground testing was performed on the PSFCC before aircraft installation. Details on the verification and validation of the PSFCC previously have been published. ${ }^{5}$

During verification and validation, two anomalies were uncovered that affected flight operations. Because the F/A-18 aircraft has a forward-loop integrator in the pitch axis, aligning the pitch integrator states of both the baseline and research control laws is necessary to prevent undesirable stabilator transients during mode transition. These stabilator transients can result in unwanted aircraft motion during the engage or disengage of the system. Verification and validation testing uncovered an oversight in the original software load that caused "drift" of the integrator alignment when the system is armed. The "drift" produced approximately $1.5 \mathrm{deg} / \mathrm{min}$ divergence between the research stabilator pitch command and the baseline computed command. Research software engagements with more than $2^{\circ}$ of drift produced noticeable, and sometimes objectionable, normal acceleration transients.

The second anomaly uncovered during verification and validation testing was traced to the initialization of a yaw-rate cancellation filter in the lateral-directional axis. In the initial PSFCC software load, this filter was not initialized prior to research control law engagement. The filter therefore required a time interval to achieve 


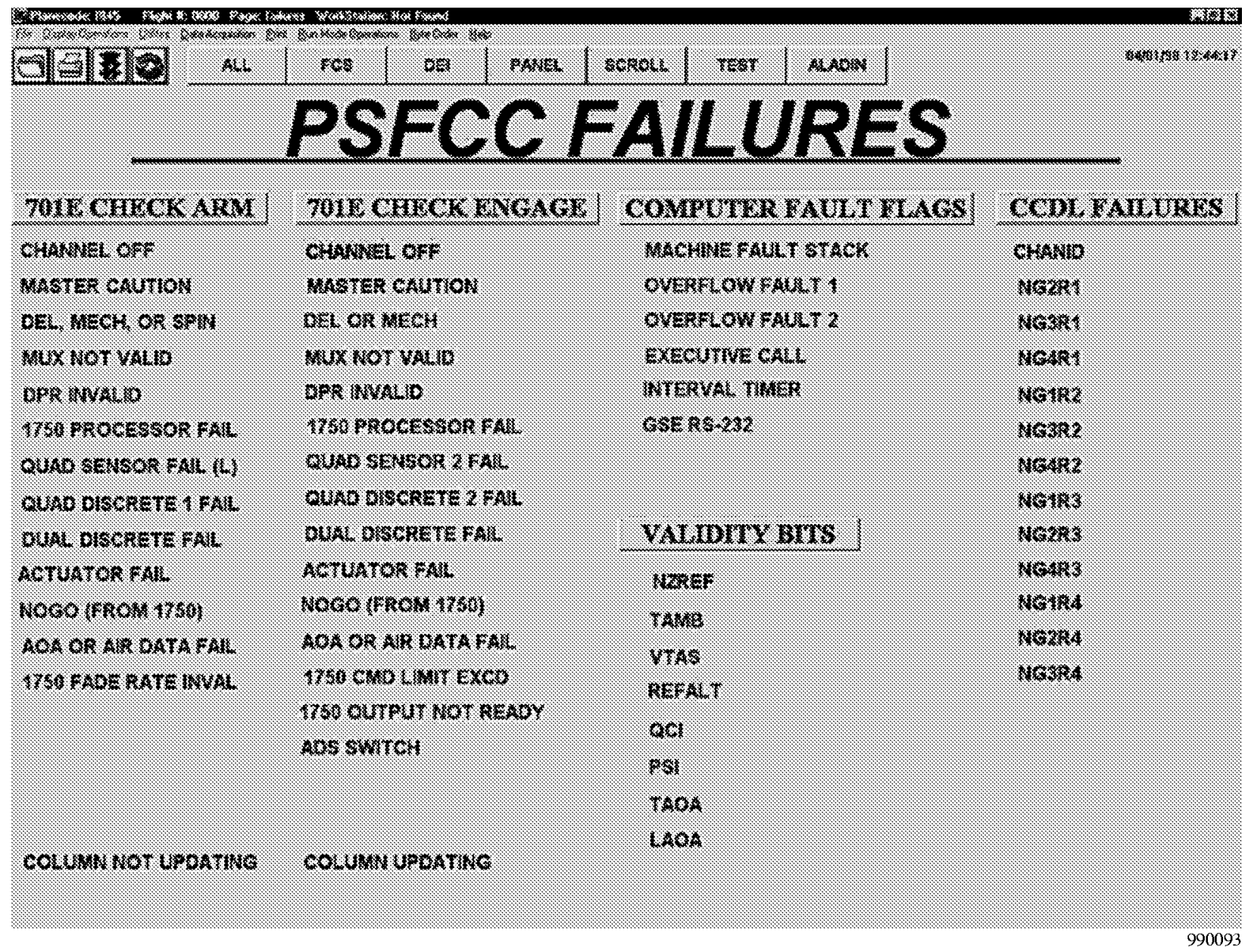

Figure 5. PSFCC hardware failure page.

steady-state values after the engagement of the research software, which resulted in a transient in directional command for a maximum of $5 \mathrm{sec}$ after engagement.

Safety issues related to these anomalies were mitigated through mission rules that specified control room concurrence between arming, engaging, and maneuvering. The two anomalies have been addressed and fixed for future PSFCC flight tests.

\section{$\underline{\text { On-Aircraft Tests }}$}

Aircraft ground tests are performed on most flight test programs to verify proper operation of aircraft systems. Checkout of these systems includes PSFCC operation, instrumentation systems, and control room displays. For the PSFCC program, a combined systems test and preflight test were performed prior to first flight.

A combined systems test is a routine ground test in which the experiment radiates telemetered instrumentation to the control room for the first time. The test is used to uncover and correct deficiencies in aircraft operation, data acquisition systems, and control room displays. The preflight test is used as a final test and checkout of aircraft systems under their own power. U. S. Navy ground testing procedures were referenced, used, and integrated into standard NASA procedures for the preflight test. The Naval Air Training and Operating Procedures Standardization (NATOPS) was used to ensure test coverage of all potentially affected aircraft systems after the installation of the PSFCC. The NATOPS-recommended tests included enginecrossbleed checks and built-in tests.

During ground engine-crossbleed checks, error codes considered unacceptable were encountered for two of four stabilator channels. The aircrew performed all standard NATOPS troubleshooting procedures with the exception of replacing flight control computers. Finding nothing objectionable, the crew recommended repeating 


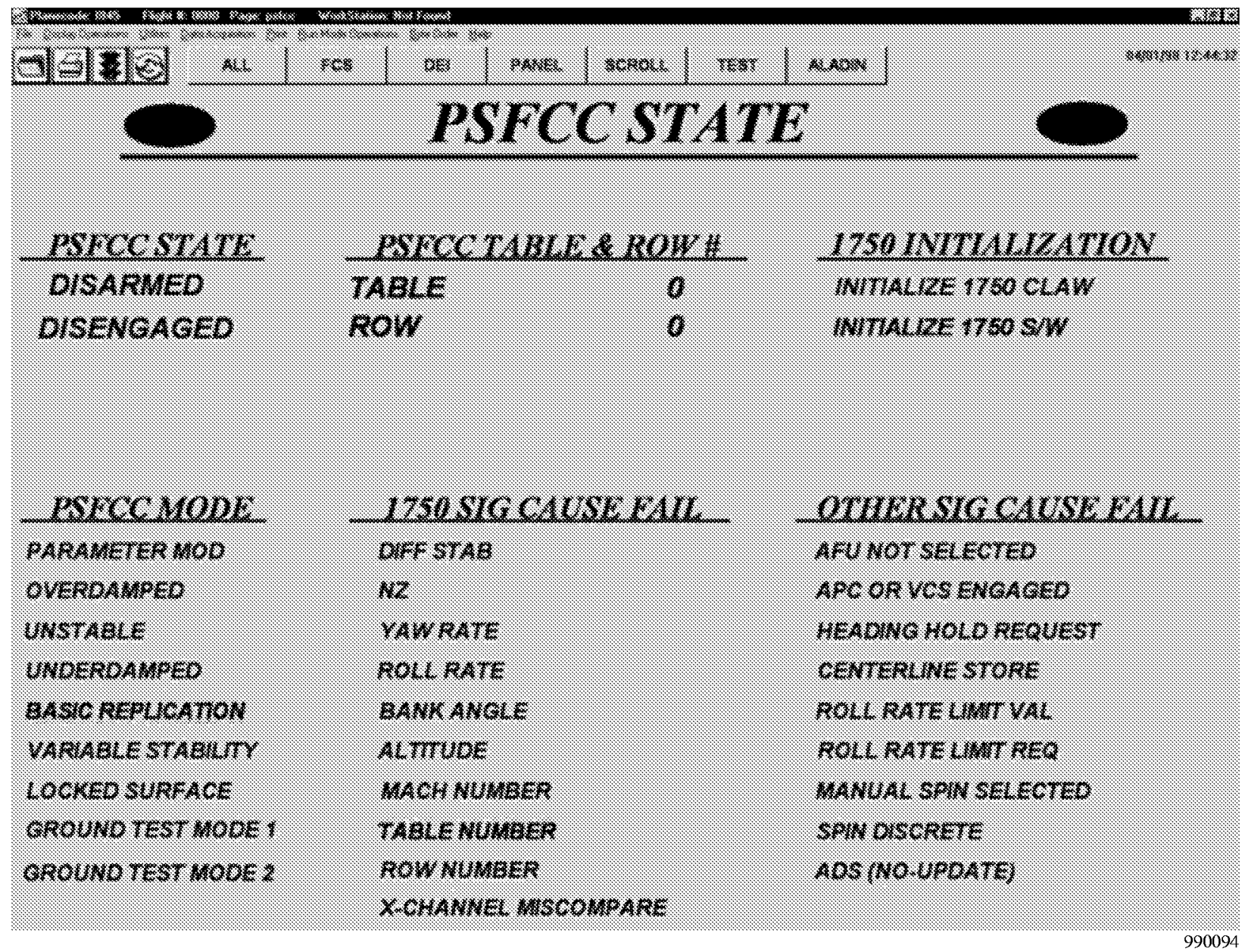

Figure 6. PSFCC 1750A research software page.

the ground test. The ground test successfully passed on the second attempt, clearing the way for first flight.

\section{Flight Test}

The PSFCC were flight-tested from March 11 to April 7, 1998. Four flights were conducted that demonstrated the basic functionality of the PSFCC within a limited flight envelope. The program consisted of three phases: FCF, PSFCC functional testing, and handling qualities testing.

\section{Functional Check Flight}

In accordance with NATOPS procedures, the aircraft performed a "profile C" FCF. The profile C FCF is used for any F/A-18 production aircraft that has had extended downtime or flight control computers replaced. The FCF consists of the following:
- Flight Control System Rig Check. Release controls and time how long rolling to a $30^{\circ}$ bank angle takes at various airspeeds. The time to roll $30^{\circ}$ was in all cases more than $8 \mathrm{sec}$ (maximum speed of $550 \mathrm{KCAS}$ ), which passed the NATOPS criterion ( $5 \mathrm{sec}$ at $550 \mathrm{KCAS}$ ).

- Flight Controls Check. Check aircraft damping with small amplitude inputs in all three axes from 300 to 350 KCAS.

- Autopilot Mode Check. Use heading hold, altitude hold, heading select, and barometric altitude hold.

- Leading-Edge Flap System Check. Windup turn to $35^{\circ}$ angle of attack to examine any difference in leading-edge flap position (criterion is $5^{\circ}$ ).

- Spin-Recovery Mode Check. Enable the spinrecovery mode switch to ensure proper operation and displays. 
- Crossbleed Airstart. Crossbleed airstart both engines.

- Trailing-Edge Flap Test. Move the flap switch to one-half and note any difference in left and right trailing-edge flap position.

- $g$ Loading Check. Pull to $+5 g$ and push to $-1 g$.

- Emergency Landing Gear Check. Check emergency landing gear operation.

Two attempts were made at the functional check flight. On the first attempt, the aircraft passed all the tests up to the crossbleed airstart. During the crossbleed airstart, the same stabilator error codes were encountered that were seen during the preflight enginecrossbleed check. The aircraft returned to base, and one of the PSFCC was replaced. A second attempt at a functional check flight was made, this time successfully. The error codes were traced to an analog card that is part of the baseline control system.

\section{Research Flight Control System Engage/Disengage Tests}

The next flight was the first evaluation of the research system and primarily consisted of arm, engagement, and disengagement tests. The initial tests were performed in the middle of the class $\mathrm{B}$ envelope, $184 \mathrm{KCAS}$ (Mach 0.45 ) at an altitude of 25,000 ft. Arming tests were performed before the engagement tests. The system was armed for $55 \mathrm{sec}$ to measure the stabilator drift, and the system was disarmed using the paddle switch.

Figure 7 shows a time history of the aircraft stabilator command and the research stabilator command during the stabilator drift test. The drift measured in flight was slightly larger than was seen in the hardware-in-the-loop simulation (approximately $1.8^{\circ}$ of drift after $55 \mathrm{sec}$ of arming), and the pilot disarm was successful. This larger drift rate was not surprising because atmospheric effects and system noise existed in flight.

In the next test, the cockpit spin-recovery mode switch was used to disarm the system successfully. Aircraft maneuvering was used to test the normal acceleration, Mach, and altitude disarm limits. The armed system was flown in a windup turn to $4.2 \mathrm{~g}$, with disarming occurring at $4.0 \mathrm{~g}$. The lower disarm limits for Mach and altitude were checked by descending slowly through an altitude of $19,000 \mathrm{ft}$, returning to the arming envelope, and then decelerating through Mach 0.4 with successful disarms.

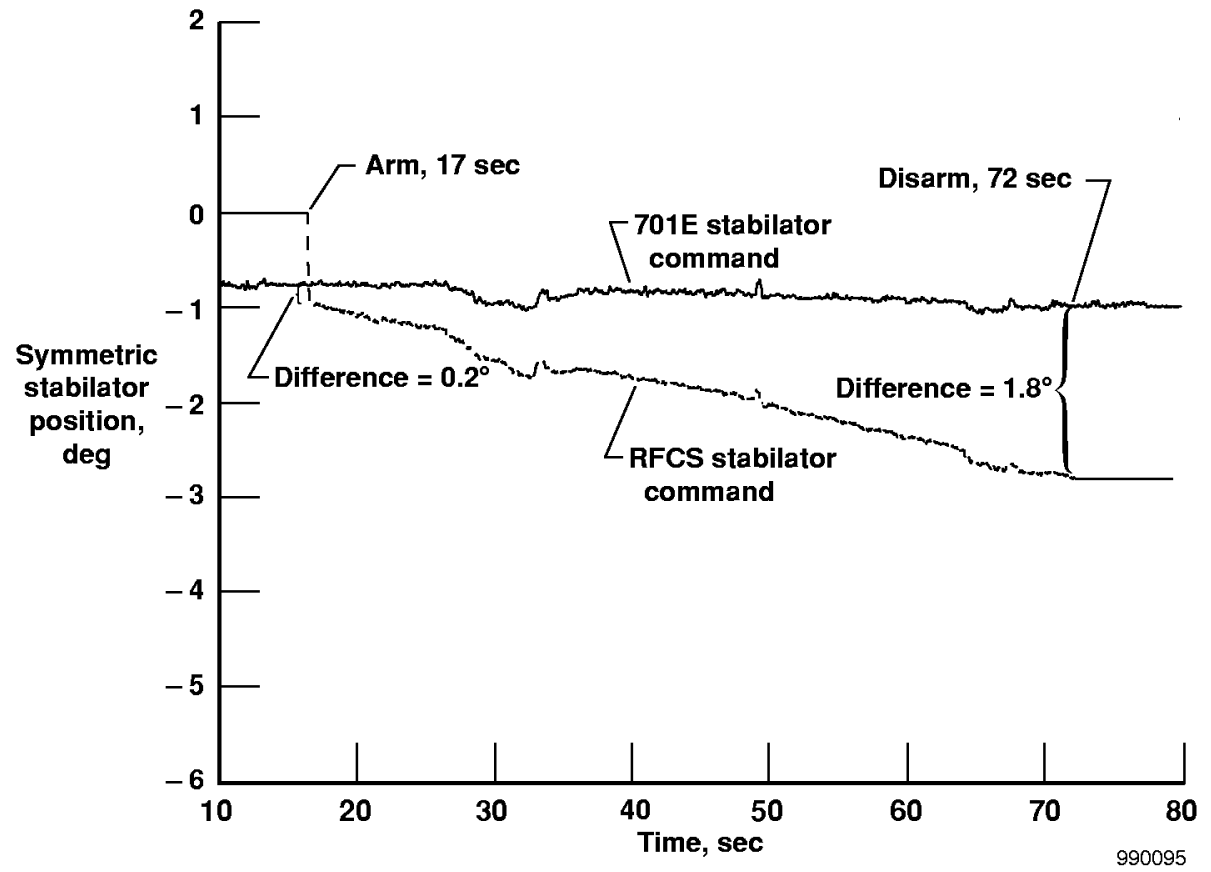

Figure 7. Integrator drift test: research flight control system and 701E stabilator commands were monitored during armed flight. 
The engagement/disengagement tests were performed in the same manner, with a disengagement altitude of $15,000 \mathrm{ft}$. The lower Mach limit of 0.2 was not tested because it would require high-angle-of-attack flight. All of the disarm/disengagement tests were performed successfully. Figure 8 shows a disengagement at approximately $4 \mathrm{~g}$ normal acceleration. Note that no noticeable transients exist in either aircraft surfaces or states. The mission rules requiring control room concurrence between arming, engaging, and maneuvering proved to be satisfactory.

\section{Handling Qualities Flights}

The remaining two flights were devoted to gathering handling qualities data. The handling qualities tests were performed at five flight conditions corresponding to the center of the five regions shown in figure 4 :

- Mach 0.45 at an altitude of 25,000 ft.

- Mach 0.55 at an altitude of $28,000 \mathrm{ft}$.
- Mach 0.45 at an altitude of $20,000 \mathrm{ft}$.

- Mach 0.40 at an altitude of $28,000 \mathrm{ft}$

- Mach 0.35 at an altitude of $20,000 \mathrm{ft}$.

For all of these flight conditions, a test maneuver block was accomplished with the baseline control software and the research control software that consisted of the following maneuvers:

- doublets in each axis.

- $0^{\circ}-60^{\circ}-60^{\circ}-0^{\circ}$ bank angle captures.

- $360^{\circ}$ rolls.

- $20^{\circ}$ pitch angle captures.

- full-pedal steady-heading sideslips.

- lateral frequency sweeps.

At Mach 0.35 and an altitude of $20,000 \mathrm{ft}$, no $360^{\circ}$ rolls were performed. For handling qualities evaluations, a qualitative comparison was made between
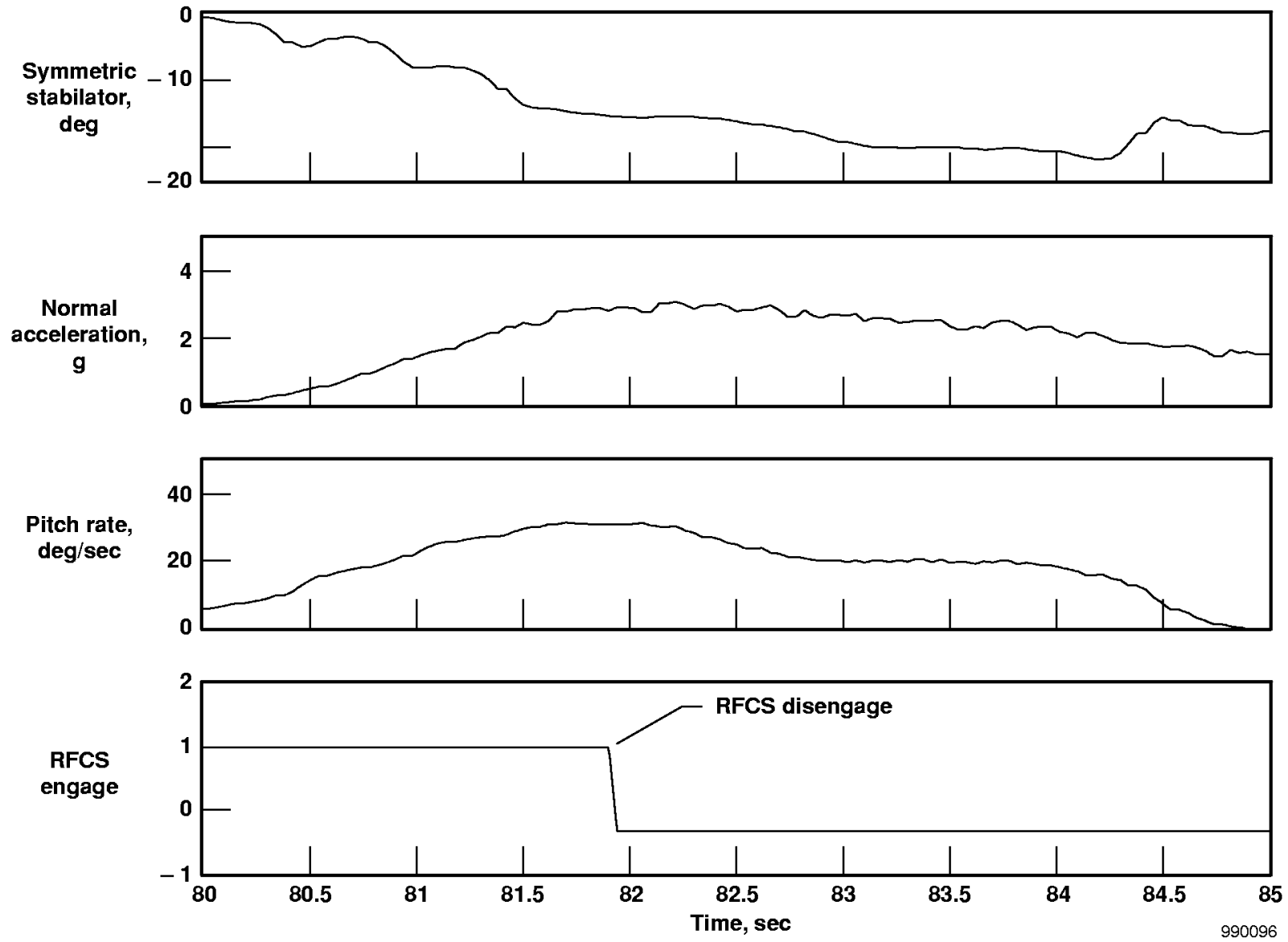

Figure 8. Windup turn, 4- $g$ disengage: no significant transients caused by research flight control system disengage. 
the standard F/A-18 and the research F/A-18 replication mode. All of the test blocks were flown back-to-back, disengaged and then engaged. The pilot was asked to describe any differences between the two flight control systems. The pilots reported no differences between the F/A-18 replication mode and the standard F/A-18 flight control system operation.

During the flight test, a number of nuisance disengagements occurred. The research processor disengaged with no baseline system error indications. The research software gave an error indication that one of the baseline computer channels had failed, although no indication was given from the baseline F/A-18 system. Further investigation is pending on these disengagements.

\section{Flight Test Data Comparisons}

In order to further verify that the F/A-18 replication mode is functioning like a standard F/A-18 mode, flight data from the PSFCC flights were used as an input to the NASA Dryden F/A-18 nonlinear six-degree-of-freedom simulation. Both the baseline system and the research F/A-18 replication software flight data were processed at the five handling qualities flight conditions. Using recorded pilot inputs, simulated time histories were calculated for comparison with flight data for rates, accelerations, and surface positions throughout the class $\mathrm{B}$ envelope. When plotting these data, the symmetric stabilator and angle-of-attack traces were biased to account for small differences in the longitudinal trim conditions between the flight data and the simulation.

Figures 9 to 11 show typical comparisons of the F/A-18 research replication software flight data to the simulation. Pilot pitch, roll, and yaw input doublets were performed in region I of the class B envelope, at Mach 0.45 and an altitude of $25,000 \mathrm{ft}$. The time histories compare symmetric and differential surface positions, pitch rate, roll rate, yaw rate, angle of attack,
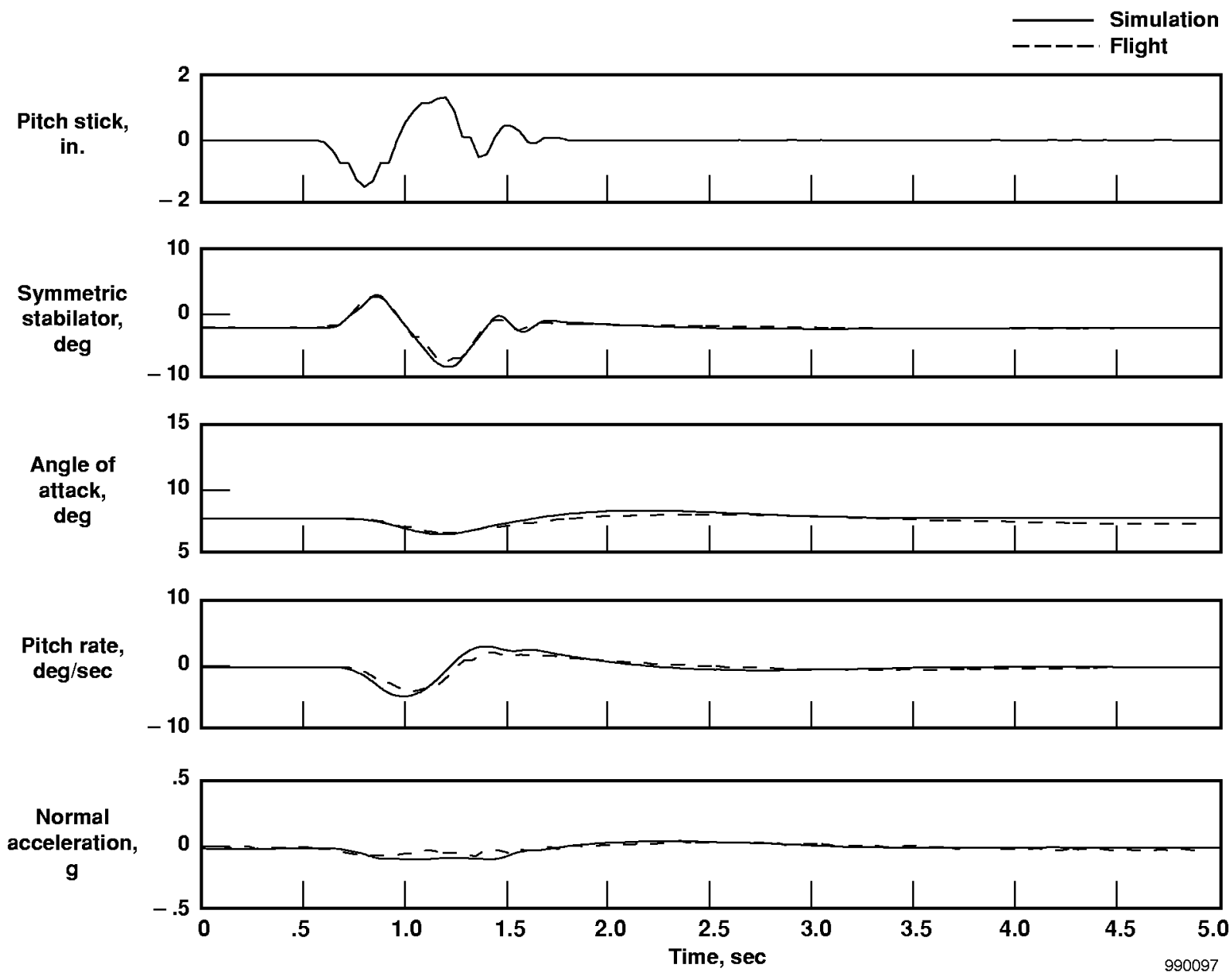

Figure 9. Simulation-to-flight comparison of a pitch doublet in research mode. 

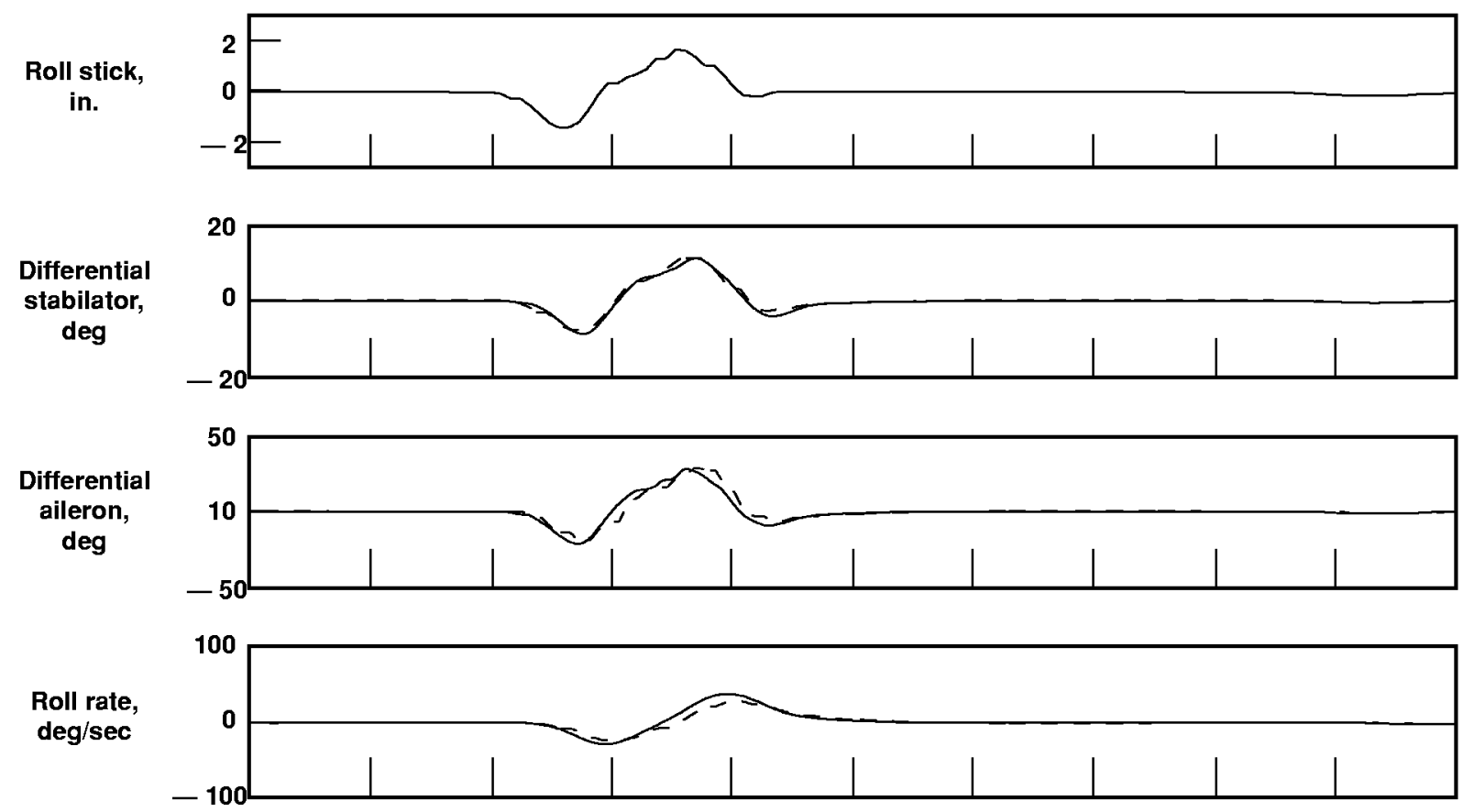

Lateral acceleration,

g

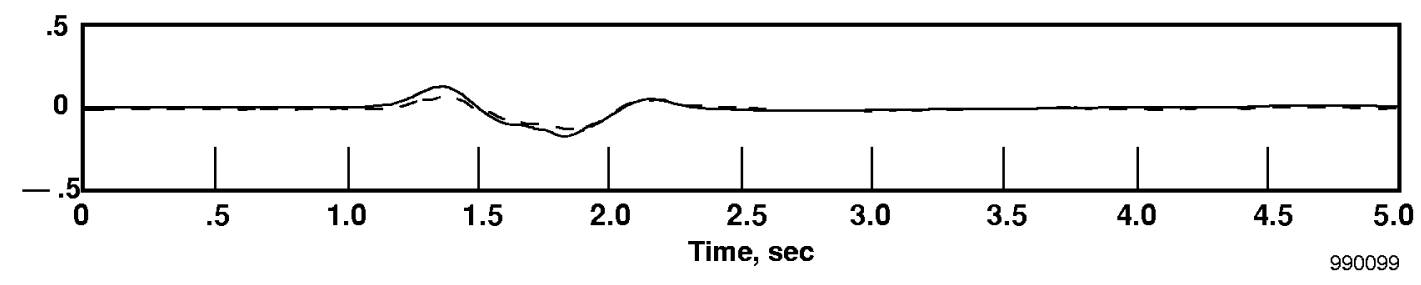

Figure 10. Simulation-to-flight comparison of a roll doublet in research mode. 

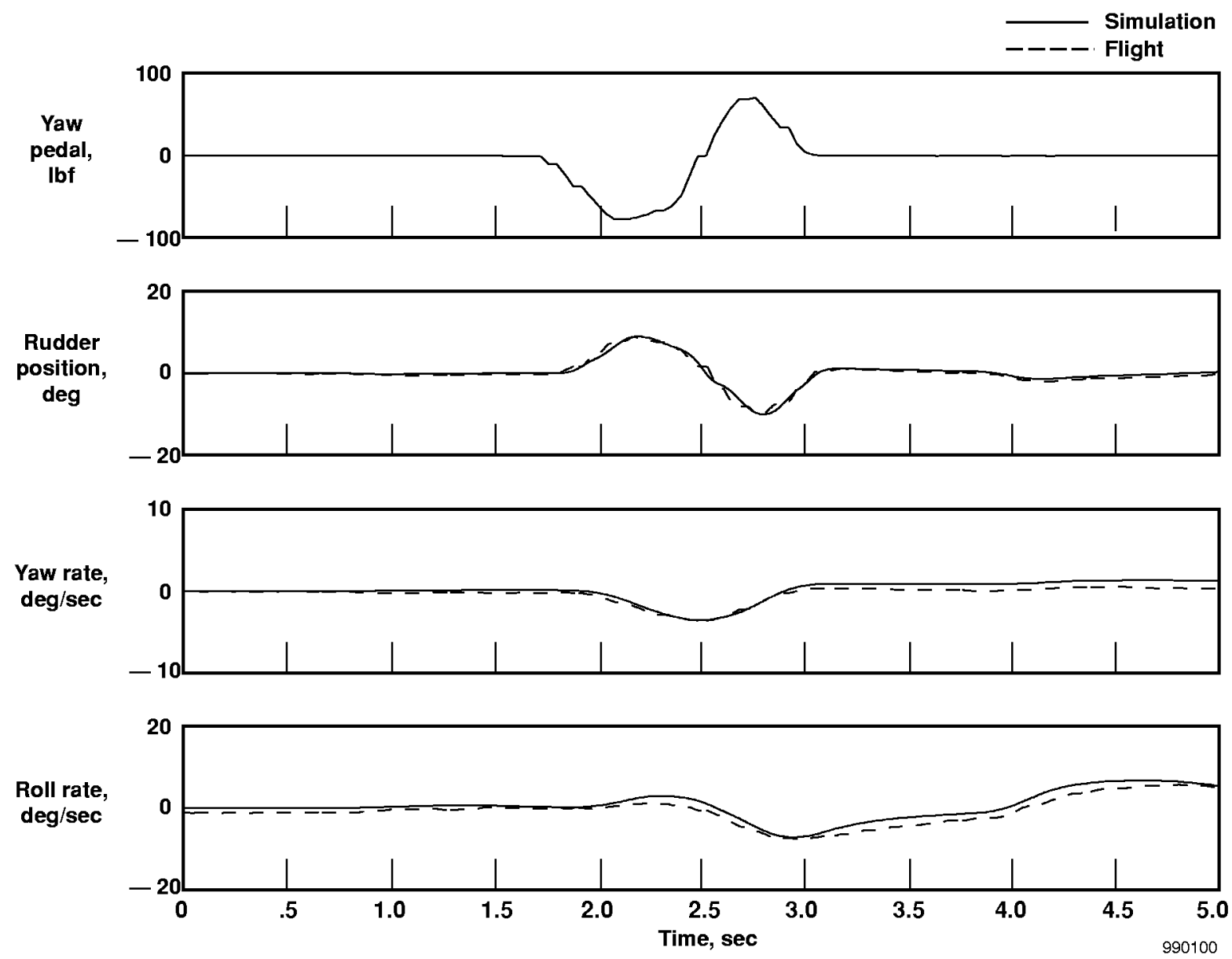

Figure 11. Simulation-to-flight comparison of yaw doublet in research mode.

and normal acceleration. These comparisons show differences between the simulated data and the flight data. The magnitude of the differences was compared for both the baseline and research software and found to be the same. Because the baseline control software and the research control software flight data show the same differences to the simulation data, the research F/A-18 control law replication mode is concluded to perform like the baseline F/A-18 control laws.

The lateral frequency sweep data were reduced and frequency responses of standard F/A-18 and research mode flight were calculated. Figure 12 shows a comparison of a frequency response of roll rate to lateral stick for both the standard F/A-18 control system and the research control law. These frequency responses showed good agreement. Because very little difference existed in the phase response, the conclusion can be made that the research software mode does not introduce any significant phase lag into the control system operation.

\section{Planned Activities for the Production Support Flight Control Computers}

Many different experiments are planned for the PSFCC in the coming years. The most immediate activity involves using the PSFCC research processor as a precision airframe surface excitation tool for aerodynamic parameter identification. Inputs can be applied to individual surfaces in a timed way to produce high-quality parameter identification data. These data will be used to refine F/A-18 aircraft aerodynamic databases for use on NASA Dryden research programs, in particular the Active Aeroelastic Wing program.

The PSFCC will also be used as a generic interface for unique flight control hardware. Analog inputs are available for interface between the research processor and external devices. Software that can interface alternate aircraft control sticks with the research processor has been written and bench-tested. NASA Dryden currently is scheduling an experiment to use a 

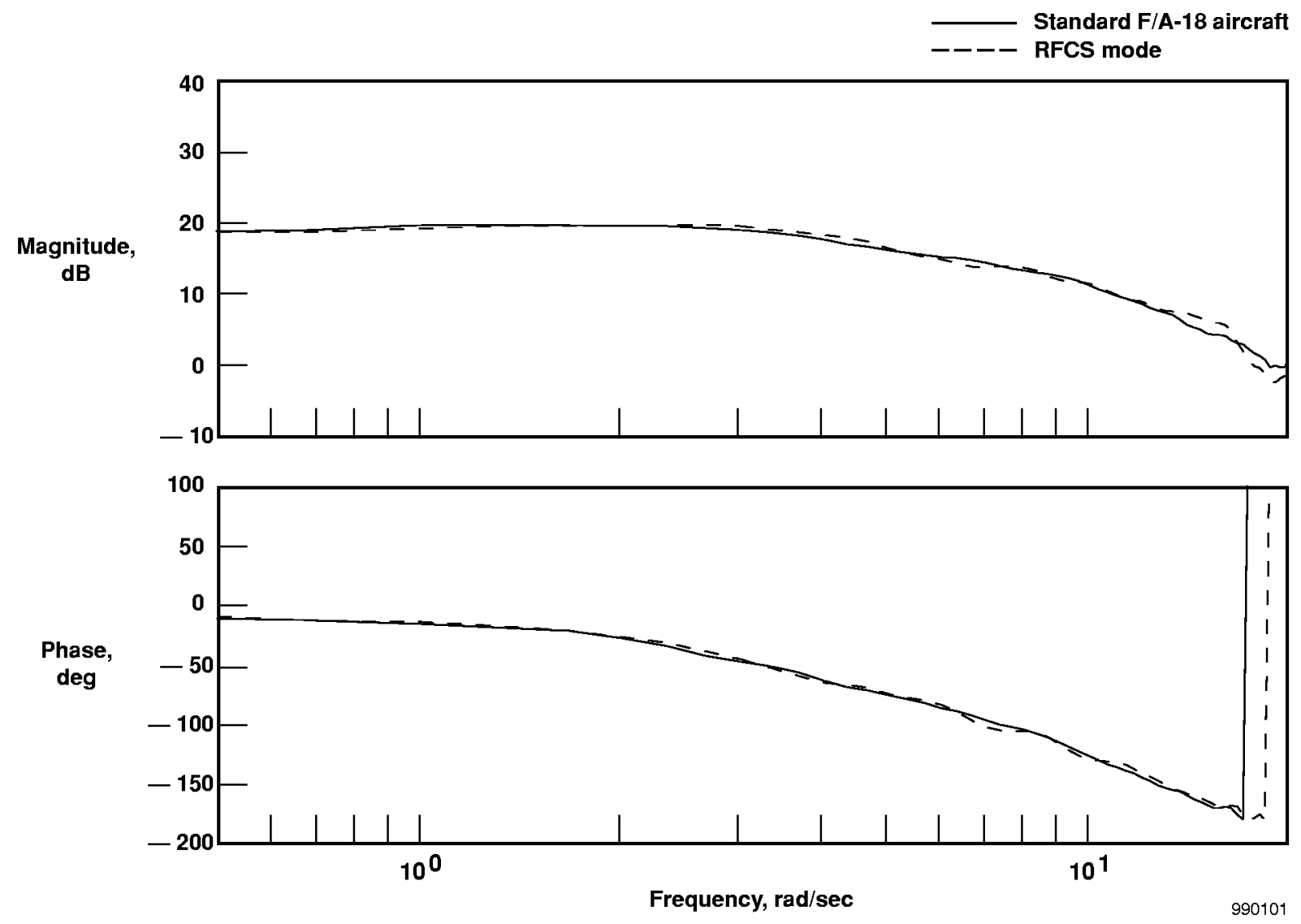

Figure 12. Frequency response of roll rate to lateral stick for standard F/A-18 and research mode flight data.

pedestal-mounted center aircraft control stick from the back seat of an F/A-18 aircraft to determine if this unique stick produces any handling qualities differences. This interface also will be used for F/A-18 autonomous formation flight experiments. Stick commands will be input through the analog inputs from a guidance computer to perform initial formation flight experiments.

An ongoing use for the PSFCC will be to flight-test experimental control law methodologies. Current proposed designs include $\mathrm{H}$ infinity and nonlinear dynamic inversion controllers. Because the F/A-18 aircraft has many surfaces that produce rolling and yawing moments, it is a very good platform for surface allocation experiments. Several surface allocation algorithms are being investigated for in-flight experiments.

\section{Conclusion}

Initial flight testing of the production support flight control computers (PSFCC) has been completed at
NASA Dryden Flight Research Center. The evaluation was done over four flights within a limited "class B" envelope. Three segments of the flight test have been performed: functional checks, PSFCC research software engagement/disengagement checks, and handling qualities assessments. The PSFCC have successfully performed a Naval Air Training and Operating Procedures Standardization "profile C" functional check flight. The engagement/disengagement logic of the PSFCC has been successfully demonstrated. Pilot comments and comparisons between flight data and NASA Dryden six-degree-of-freedom simulation time histories and lateral frequency response data indicate that the research F/A-18 replication software operates the same way as the F/A-18 standard flight control system for the envelope tested.

Two software anomalies (the integrator drift and yawaxis filter initialization) were encountered during the ground testing but were remedied through procedure. The flight integrator drift was greater than the drift 
found during bench testing, but presented no operational problems during flight test. No undesirable lateral-directional transients caused by the yaw filter initialization occurred during flight test. Both of these anomalies will be fixed in the next research software version. Nuisance disengages were encountered during the flight test; they are currently being investigated.

A variety of experiments are planned for the PSFCC. The PSFCC will be used to refine the F/A-18 aerodynamic database by providing in-flight surface inputs for aerodynamic parameter identification. Alternate pilot control sticks will be used with the PSFCC to investigate their effects on F/A-18 handling qualities. Some F/A-18 autonomous formation flight experiments will be performed using PSFCC to interface between the formation flight guidance algorithms and the baseline aircraft system. Experimental control law architectures and surface allocation algorithms will be flight-tested using this research flight control computer system. This initial flight test proved the viability of the PSFCC for generic flight controls and flight systems research and was the first step for many future flight research programs.

\section{$\underline{\text { References }}$}

${ }^{1}$ Shafer, Mary F, In-Flight Simulation Studies at the NASA Dryden Flight Research Facility, NASA TM-4396, 1992.

${ }^{2}$ Markman, Steve and Bill Holder, One-of-a-Kind Research Aircraft: A History of In-Flight Simulators, Testbeds, and Prototypes, Schiffer Publishing Ltd., Atglen, PA, 1995.

${ }^{3}$ Pahle, Joseph W., Bruce Powers, Victoria Regenie, Vince Chacon, Steve Degroote, and Steven Murnyak, Research Flight-Control System Development for the F-18 High Alpha Research Vehicle, NASA TM-104232, 1991.

${ }^{4}$ Regenie, Victoria A., Michael Earls, Jeanette Le, and Michael Thomson, Experience With Ada on the F-18 High Alpha Research Vehicle Flight Test Program, NASA TM-104259, 1992.

${ }^{5}$ Carter, John F., Production Support Flight Control Computers: Research Capability for F/A-18 Aircraft at Dryden Flight Research Center, NASA TM-97-206233, 1997. 
Public reporting burden for this collection of information is estimated to average 1 hour per response, including the time for reviewing instructions, searching existing data sources, gathering and maintaining the data needed, and completing and reviewing the collection of information. Send comments regarding this burden estimate or any other aspect of this collection of information, including suggestions for reducing this burden, to Washington Headquarters Services, Directorate for Information Operations and Reports, 1215 Jefferson Davis Highway, Suite 1204, Arlington, VA 22202-4302, and to the Office of Management and Budget, Paperwork Reduction Project (0704-0188), Washington, DC 20503

1. AGENCY USE ONLY (Leave blank)

2. REPORT DATE

3. REPORT TYPE AND DATES COVERED

August 1999

Technical Memorandum

4. TITLE AND SUBTITLE

Initial Flight Test of the Production Support Flight Control Computers at

NASA Dryden Flight Research Center

6. AUTHOR(S)

WU 529-30-24-00-36-00-SRA

John Carter and Mark Stephenson

7. PERFORMING ORGANIZATION NAME(S) AND ADDRESS(ES)

NASA Dryden Flight Research Center

P.O. Box 273

Edwards, California 93523-0273

8. PERFORMING ORGANIZATION

REPORT NUMBER

H-2343

9. SPONSORING/MONITORING AGENCY NAME(S) AND ADDRESS(ES)

10. SPONSORING/MONITORING AGENCY REPORT NUMBER

National Aeronautics and Space Administration

Washington, DC 20546-0001

NASA/TM-1999-206581

11. SUPPLEMENTARY NOTES

Presented as AIAA 99-4203 at the AIAA Guidance, Navigation, and Control Conference, Portland, Oregon, August 9-11, 1999.

12a. DISTRIBUTION/AVAILABILITY STATEMENT

12b. DISTRIBUTION CODE

Unclassified-Unlimited

Subject Category 08

13. ABSTRACT (Maximum 200 words)

The NASA Dryden Flight Research Center has completed the initial flight test of a modified set of F/A-18 flight control computers that gives the aircraft a research control law capability. The production support flight control computers (PSFCC) provide an increased capability for flight research in the control law, handling qualities, and flight systems areas. The PSFCC feature a research flight control processor that is "piggybacked" onto the baseline F/A-18 flight control system. This research processor allows for pilot selection of research control law operation in flight. To validate flight operation, a replication of a standard F/A-18 control law was programmed into the research processor and flight-tested over a limited envelope. This paper provides a brief description of the system, summarizes the initial flight test of the PSFCC, and describes future experiments for the PSFCC.

\section{SUBJECT TERMS}

Aircraft testing, Control law research, F/A-18, Flight control, Production support flight control computers

\begin{tabular}{|l|l|l|}
\hline $\begin{array}{l}\text { 17. SECURITY CLASSIFICATION } \\
\text { OF REPORT }\end{array}$ & $\begin{array}{l}\text { 18. SECURITY CLASSIFICATION } \\
\text { OF THIS PAGE } \\
\text { Unclassified }\end{array}$ & $\begin{array}{l}\text { 19. SECURITY CLASSIFICATION } \\
\text { OF ABSTRACT } \\
\text { Unclassified }\end{array}$ \\
\hline
\end{tabular}

15. NUMBER OF PAGES

20

16. PRICE CODE

$\mathrm{A} 03$

20. LIMITATION OF ABSTRACT

Unlimited 